\title{
Effects of various dietary n-3/n-6 fatty acid ratios on the performance and body composition of broilers
}

\author{
G.J.M. Coetzee and L.C. Hoffman ${ }^{\#}$ \\ Department of Animal Sciences, University of Stellenbosch, P. Bag X1, Matieland 7602, South Africa
}

\begin{abstract}
Different combinations of saturated and unsaturated fatty acids were fed to broilers to establish their effect on the fatty acid composition of the broiler carcass and the abdominal fat pad. Six combinations of Canola acid oil (CAO, high levels of C18:3n-3 and monounsaturated fatty acids) and Famarol acid oil (FAO, high levels of C18:2n-6 and saturated fatty acids) were included in the broiler diets from one day of age to six weeks of age, viz. 100\% FAO, 80\% FAO-20\% CAO, 60\% FAO- $40 \%$ CAO, 40\% FAO-60\% CAO, 20\% FAO- $80 \%$ CAO, 100\% CAO. There were no statistically significant differences between dietary groups in weight gain $(1.71 \pm 0.059 \mathrm{~kg})$ or feed conversion ratios $(1.97 \pm 0.051 \mathrm{~g}$ feed $/ \mathrm{g}$ gain $)$. No significant differences between treatments were found in the moisture $(66.20 \pm 0.112 \%)$, protein $(17.63 \pm 0.484 \%)$, lipid $(15.92 \pm 1.507 \%)$ and ash $(0.95 \pm 0.115 \%)$ concentration of the carcasses, nor in the moisture $(28.77 \pm$ $0.112 \%)$, protein $(3.03 \pm 0.484 \%)$, lipid $(63.32 \pm 9.789 \%)$ and ash $(0.45 \pm 0.135 \%)$ concentrations of the abdominal fat pads. With the increase in dietary CAO levels, the mean percentages of C18:2n-6 and C20:4n6 in the carcasses decreased respectively with $1.78 \%$ units from $20.88 \%$ and $0.35 \%$ units from $1.05 \%$, whilst C18:3n-3 and longer chain n-3 fatty acids such as C20:5n-3 and C22:6n-3 increased respectively with $2.25 \%$ units from $1 \%, 0.1 \%$ units from $0.1 \%$ and $0.67 \%$ units from $0.2 \%$. The same tendency was seen in the abdominal fat pads where C18:2n-6 and C20:4n-6 decreased respectively with $1.55 \%$ units from $20.75 \%$ and $0.98 \%$ units from $1.2 \%$ with an increase in dietary CAO, whilst C18:3n-3, C20:5n-3 and C22:6n-3 increased respectively with $2.13 \%$ units from $1.15 \%, 0.45 \%$ units from $0.03 \%$ and $0.95 \%$ units from $0.05 \%$. The $n-3 / n-$ 6 ratio in the carcasses and abdominal fat pads increased respectively with $0.16 \%$ units from $0.06 \%$ and $0.19 \%$ units from $0.06 \%$ with an increase in dietary CAO. These results clearly indicate that dietary CAO enriched with $\alpha$-linolenic acid lowered the saturated fatty acid concentrations in broiler carcasses and abdominal fat pads with $4.88 \%$ units and $10.63 \%$ units respectively, and increased the monounsaturated fatty acid concentrations with $3.87 \%$ units and $7.25 \%$ units, respectively and polyunsaturated fatty acid concentrations with $1.02 \%$ units and $2.38 \%$ units, respectively. The results of this experiment showed that substitution of Famarol oil with Canola oil in broiler diets can increase the ratio of n- 6 to $n-3$ fatty acids in broiler carcasses and abdominal fat pads to 5:1, a ratio more suitable for human health. Increasing the level of n-3 fatty acids in the diets was also effective in reducing the level of saturated fatty acids in the carcasses and abdominal fat pads of broiler chickens resulting in "healthier" chickens.
\end{abstract}

Keywords: Broiler meat, n-3/n-6, fatty acids

${ }^{\#}$ Corresponding author. E-mail: lch@sun.ac.za

\section{Introduction}

Potentially one of the most important fields of study in animal nutrition is that of the effects of diet on the fatty acid composition of the animal carcass. This information is mainly of value because of an imbalance in the human dietary intake of various types of fatty acids (Simopoulus, 1991). There is much interest in the relative merits of monounsaturated, n-6 polyunsaturated and n-3 polyunsaturated fatty acids (PUFA) in human nutrition and their role in protecting the human body against cardiovascular related diseases (Wiseman, 1997). Several sources of information suggest that man evolved on a diet with a ratio of n-6 to n-3 fatty acids of $\sim 1$, whereas today this ratio is $\sim 10: 1$ to 20-25:1 (Simopoulus, 1991). This suggests that Western diets are deficient in n-3 fatty acids compared with the diet on which humans evolved and their genetic parameters were established. It is thus important for human health to increase the consumption of n-3 fatty acids.

Dietary fatty acids are absorbed by monogastric animals and deposited in their tissues without significant modification. There is, therefore, considerable potential for the manipulation of the fatty acid profiles of poultry tissue by dietary means, thus to increase the supply of n-3 PUFA suitable for human consumption. Ajuyah et al. (1991) showed that the use of linseed oil or whole linseed in poultry diets resulted in tissue enrichment of n-3 PUFA (C20:5n-3 and C22:6n-3) derived from C18:3n-3 by desaturation 
and elongation. Hulan et al. (1989) indicated that marine oils and fish meal containing residual lipid increased the $\mathrm{C} 20$ and $\mathrm{C} 22$ n-3 PUFA concentration of poultry tissue.

In the present study, different levels of two commercial acid oil blends, Canola and Famarol, were fed to broiler chickens to examine their influence on the performance and fatty acid composition of the bodily fat in the birds.

\section{Materials and methods}

A total of 216 one-day-old, vent sexed male and female broilers were reared for 42 days in an environmentally controlled rearing house. Six birds per cage were allocated to 36 cages, 18 cages containing males and 18 containing females. All the birds in each cage were allocated to one of six dietary treatments. A randomised block design was used. The nutrient composition of the experimental diets is given in Table 1 .

Table 1 Calculated nutrient composition of the experimental broiler diet

\begin{tabular}{lc}
\hline & Composition of diet \\
Nutrient & $\mathrm{g} / \mathrm{kg}$ \\
\hline Metabolisable energy $(\mathrm{MJ} / \mathrm{kg})$ & 13.2 \\
Protein & 229 \\
Arginine & 14.5 \\
Isoleucine & 9.8 \\
Leucine & 23.8 \\
Lysine & 11.5 \\
Methionine & 5.7 \\
Methionine + Cystine & 9.5 \\
Threonine & 7.7 \\
Tryptophan & 2.3 \\
Calcium & 8.9 \\
Sodium & 1.6 \\
Phosphorus & 4.0 \\
Water & 92.0 \\
\hline
\end{tabular}

Table 2 The formulation of the basal broiler diet (as fed)

\begin{tabular}{lc}
\hline & Composition of diet \\
Ingredient & $\mathrm{g} / \mathrm{kg}$ \\
\hline Gluten 60 & 82 \\
Feed lime & 13 \\
Coccidiostat & 2 \\
Lysine & 5 \\
Maize & 512 \\
Mono-dicalcium phosphate & 13 \\
Synthetic methionine & 2 \\
Soybean meal & 176 \\
Fine salt & 4 \\
Sunflower meal & 109 \\
Vitamin/mineral mix ${ }^{1}$ & 4 \\
Oil mixture & 80 \\
\hline Vitamin/mineral mix: Vitamin A (10 000 000 IU), vitamin D \\
(2 000 000 IU), vitamin E (20 000 IU), vitamin K (2 g), \\
vitamin B1 (2 g), vitamin B2 (5 g), vitamin B6 (3 g), vitamin \\
B12 (0.01 g), niacin (20 g), calpan DL (10 g), folic acid (0.5 \\
g), biotin (0.02 g), antioxidant (125 g), choline (300 g), cobalt \\
(0.5 g), copper (6 g), iron (20 g), manganese (70 g), iodine (1 \\
g), selenium (0.15 g), zinc (50 g).
\end{tabular}

The basic formulation of the experimental diets (Table 2) contained supplemental ratios of Famarol acid oil (FAO):Canola acid oil (CAO) namely 100:0, 80:20, 60:40, 40:60, 20:80 and 0:100. Both the Famarol and Canola oil are acid oils. Acid oils are by-products of the chemical refining of crude oils. During the 
process, the crude oil is first treated with water to remove gums and other water-soluble components. The free fatty acids are then removed by the addition of a weak alkali solution, converting them to water soluble soap. The resultant soap-stock is then treated with acid to convert the soap back to free fatty acids. Acid oils may derive from a single source, such as the $\mathrm{CAO}$, or it may be derived from a mixture of acid oils. Famarol acid oil is mainly a mixture of different vegetable and marine oils. Both oils were obtained from commercial oil refineries in Cape Town, South Africa

Bird weights per cage and food consumption per cage were recorded weekly. Weight gain (WG) and feed conversion ratios (FCR) were calculated. A 24-hour light period was followed. The starting temperature at day-old was $33^{\circ} \mathrm{C}$ and was gradually decreased to $21{ }^{\circ} \mathrm{C}$ at $21 \mathrm{~d}$ of age. A standard commercial health and inoculation program was followed.

All six birds from each cage were slaughtered at $42 \mathrm{~d}$ of age. The weight of the plucked birds was recorded (excluding head, legs, digestive tract and content) and the abdominal fat pad removed and weighed. The six carcasses (including bone, muscle, skin and subcutaneous fat) and abdominal fat pads from each cage were minced, pooled and stored at $-20{ }^{\circ} \mathrm{C}$ for chemical analysis. The carcass tissue, abdominal fat pads and feed of each cage were analysed for moisture $\left(105^{\circ} \mathrm{C}, 24 \mathrm{~h}\right)$, nitrogen (protein = nitrogen $\left.\mathrm{x} 6.25\right)$ and ash (AOAC., 1995) concentrations. The samples were analysed also for total lipid (using chloroform / methanol 2:1 as solvent) content, using the method of Lee et al. (1996). The lipids in the tissue, abdominal fat pads and feed were analysed for fatty acid concentration. Fatty acid methyl esters (FAME) were prepared according to the method proposed by Morrison \& Smith (1964). The FAME were analysed with a GLC (Varian Model 3300) equipped with flame ionisation detection and two $30 \mathrm{~m}$ fused silica megabore DB-225 columns of 0.53 $\mathrm{mm}$ internal diameter ( $\mathrm{J} \& \mathrm{~W}$ Scientific, Folsom, CA). Gas flow rates were: hydrogen, $25 \mathrm{ml} / \mathrm{min}$; air, 250 $\mathrm{ml} / \mathrm{min}$; and nitrogen (carrier gas), $5-8 \mathrm{ml} / \mathrm{min}$. Temperature programming was linear at $4{ }^{\circ} \mathrm{C} / \mathrm{min}$; initial temperature, $160{ }^{\circ} \mathrm{C}$; final temperature, $220{ }^{\circ} \mathrm{C}$ held for $10 \mathrm{~min}$; injector temperature, $240{ }^{\circ} \mathrm{C}$; and detector temperature, $250^{\circ} \mathrm{C}$. The FAME concentrations were identified by comparing the retention times to those of a standard FAME mixture (Nu-Chek-Prep Inc., Elysian, Minnesota).

A linear regression model was fitted to the data with diet (lipid variations) as predictor. Analyses of variance were performed on all the variables measured, using the General Linear Models (GLM) procedure of SAS (1985). The following model was fitted for main effects (diet, sex) and the interaction between them:

$$
Y_{i j}=\mu+D_{i}+S_{j}+D_{i j}+e_{i j}
$$

Where:

$\mathrm{Y}_{\mathrm{ij}}$ is the dependent variable,

$\mu=$ the overall mean,

$\mathrm{D}_{\mathrm{i}}=$ the $\mathrm{i}^{\text {th }}$ diet effect,

$S_{j}=$ the $j^{\text {th }}$ sex effect,

$\mathrm{DS}_{\mathrm{ij}}=$ the interaction between diet and sex,

$\mathrm{e}_{\mathrm{ij}}=$ the residual error.

The differences between diets and sexes were tested separately by means of the null hypothesis $\left(\mathrm{H}_{0}\right)$, with $\mathrm{H}_{0}: \mu=\mu_{0}$ and the alternate hypothesis $\left(\mathrm{H}_{\mathrm{a}}\right)$ being $\mathrm{H}_{\mathrm{a}}: \mu \neq \mu_{0}$. Mean and standard errors were calculated for each diet and sex and a matrix of excedence probabilities were calculated to test for differences with Student's $t$ test. Differences between the variables were accepted as being significant if the probability of rejection of $\mathrm{H}_{0}$ was less than $5 \%(\mathrm{P}<0.05)$ for diets and sex.

\section{Results}

The weight gain (WG) and feed conversion ratio (FCR) of broilers fed the different experimental diets are shown in Table 3. There were no significant differences $(P>0.05)$ in WG or FCR among the dietary and sex groups. No significant statistical interaction was found between diet and sex for WG and FCR.

In Table 4 the proximate composition of the carcasses, abdominal fat pads and feed of the broilers is presented. There were no significant differences $(\mathrm{P}>0.05)$ in the protein, ash, moisture or lipid concentration of the carcasses and fat pads among the different dietary groups. 
Table 3 Effects of various FAO/CAO ratios in the diets on weight gain (WG, $\mathrm{kg}$ ) and feed conversion ratio (FCR, $\mathrm{g}$ feed/g gain) of broilers

\begin{tabular}{lccccccc}
\hline \multicolumn{7}{c}{ Ratio of FAO:CAO } \\
& $100: 0$ & $80: 20$ & $60: 40$ & $40: 60$ & $20: 80$ & $0: 100$ & s.e. \\
\hline WG & 1.82 & 1.67 & 1.66 & 1.71 & 1.68 & 1.70 & 0.047 \\
FCR & 1.91 & 1.94 & 2.00 & 2.05 & 1.99 & 1.94 & 0.041 \\
\hline
\end{tabular}

FAO - Famarol acid oil, CAO - Canola acid oil

Table 4 Effects of FAO/CAO ratios in the diets on the proximate composition of carcasses and abdominal fat pads (AFP) of broilers, (fresh weight basis) and feeds

\begin{tabular}{|c|c|c|c|c|c|c|c|}
\hline \multicolumn{8}{|c|}{ Ratio of FAO:CAO } \\
\hline & $100: 0$ & $80: 20$ & $60: 40$ & $40: 60$ & $20: 80$ & $0: 100$ & s.e. \\
\hline \multicolumn{8}{|l|}{ Moisture \% } \\
\hline Carcass & 66.34 & 66.14 & 66.10 & 66.12 & 66.34 & 66.14 & 0.031 \\
\hline AFP & 28.91 & 28.71 & 28.67 & 28.69 & 28.91 & 28.71 & 0.043 \\
\hline Feed & 10.44 & 10.46 & 10.20 & 10.24 & 10.27 & 10.21 & \\
\hline \multicolumn{8}{|l|}{ Protein \% } \\
\hline Carcass & 18.19 & 17.41 & 17.62 & 16.96 & 18.19 & 17.41 & 0.424 \\
\hline AFP & 3.59 & 2.81 & 3.02 & 2.36 & 3.59 & 2.81 & 0.241 \\
\hline Feed & 19.51 & 19.19 & 19.52 & 19.05 & 18.86 & 18.79 & \\
\hline \multicolumn{8}{|l|}{ Lipid \% } \\
\hline Carcass & 18.09 & 16.40 & 16.45 & 15.29 & 15.77 & 13.53 & 1.443 \\
\hline AFP & 61.51 & 57.84 & 54.12 & 81.12 & 58.01 & 67.34 & 5.777 \\
\hline Feed & 9.85 & 8.21 & 14.92 & 9.62 & 10.18 & 9.12 & \\
\hline \multicolumn{8}{|l|}{ Ash \% } \\
\hline Carcass & 0.85 & 1.05 & 1.07 & 0.84 & 0.85 & 1.05 & 0.132 \\
\hline AFP & 0.33 & 0.53 & 0.65 & 0.35 & 0.33 & 0.53 & 0.108 \\
\hline Feed & 5.96 & 6.10 & 6.36 & 6.17 & 6.10 & 6.17 & \\
\hline
\end{tabular}

FAO - Famarol acid oil, CAO - Canola acid oil

Table 5 Fatty acid profiles of Famarol oil and Canola oil used in the diets (\% recoverable fatty acids)

\begin{tabular}{lcc}
\hline & Famarol oil & Canola oil \\
\hline Saturated fatty acids & & \\
C12:0 & 0.29 & - \\
C14:0 & 0.46 & 0.07 \\
C16:0 & 13.72 & 5.34 \\
C18:0 & 4.43 & 2.40 \\
C20:0 & 0.75 & 0.35 \\
C22:0 & 0.65 & - \\
Total (S) & 20.3 & 8.16 \\
Unsaturated fatty acids & & \\
C18:1n-9 & 38.72 & 58.82 \\
C18:2n-6 & 31.70 & 21.08 \\
C18:3n-3 & 8.08 & 10.81 \\
C20:1n-9 & 0.81 & 0.41 \\
Total (U) & 79.31 & 91.12 \\
& & \\
U:S & 3.9 & 11.2 \\
n-3/n-6 & 0.25 & 0.51 \\
Unknowns & 0.39 & 0.72 \\
\hline
\end{tabular}

The fatty acid profiles of the two oils (Table 5) added to the experimental diet (Table 1) differed substantially. Canola acid oil contained high concentrations of $\alpha$-linolenic acid (C18:3n-3) and monounsaturated fatty acids (MUFA), while Famarol oil contained high concentrations of linoleic acid (C18:2n-6) and saturated fatty acids. This resulted in the various treatments containing different mixtures of $\mathrm{CAO}$ and FAO (Table 6) and having a large variation in lipid composition, particularly the level of saturation. 
Table 6a The saturated fatty acid (SFA) composition of the feeds, carcass and abdominal fat pad (AFP) total lipid from broilers receiving different dietary lipid variations of Famarol (FAO) and Canola (CAO) fatty

\begin{tabular}{|c|c|c|c|c|c|c|c|}
\hline \multicolumn{8}{|c|}{$\frac{\text { acids }}{\text { Ratio of FAO:CAO }}$} \\
\hline Fatty acids* & 100:0 & $80: 20$ & $60: 40$ & $40: 60$ & $20: 80$ & $0: 100$ & s.e. \\
\hline \multicolumn{8}{|l|}{ C14:0 } \\
\hline$\overline{\text { Carcass }}$ & $1.05^{\mathrm{a}}$ & $1.22^{\mathrm{a}}$ & $2.07^{\mathrm{b}}$ & $1.38^{\mathrm{ac}}$ & $1.45^{\mathrm{ad}}$ & $1.67^{\mathrm{bcd}}$ & 0.170 \\
\hline AFP & $1.75^{\mathrm{a}}$ & $1.58^{\mathrm{a}}$ & $1.35^{\mathrm{ab}}$ & $0.80^{\mathrm{c}}$ & $0.98^{\mathrm{bc}}$ & $0.98^{\mathrm{bc}}$ & 0.156 \\
\hline Feed & 1.42 & 1.42 & 1.72 & 1.10 & 1.27 & 1.35 & \\
\hline \multicolumn{8}{|l|}{ C16:0 } \\
\hline Carcass & $23.98^{\mathrm{a}}$ & $23.38^{\mathrm{b}}$ & $22.57^{\mathrm{c}}$ & $21.73^{\mathrm{d}}$ & $20.65^{\mathrm{e}}$ & $20.08^{f}$ & 0.116 \\
\hline AFP & $22.95^{\mathrm{a}}$ & $21.25^{\mathrm{b}}$ & $19.72^{c}$ & $17.75^{\mathrm{d}}$ & $16.78^{\mathrm{e}}$ & $15.28^{\mathrm{f}}$ & 0.125 \\
\hline Feed & 23.38 & 22.30 & 21.08 & 19.68 & 8.68 & 17.70 & \\
\hline \multicolumn{8}{|l|}{ C18:0 } \\
\hline$\overline{\text { Carcass }}$ & $6.57^{\mathrm{a}}$ & $6.15^{\mathrm{b}}$ & $5.68^{\mathrm{c}}$ & $5.37^{\mathrm{d}}$ & $5.15^{\mathrm{e}}$ & $4.97^{\mathrm{f}}$ & 0.061 \\
\hline AFP & $6.40^{\mathrm{a}}$ & $5.95^{\mathrm{b}}$ & $5.40^{\mathrm{c}}$ & $4.95^{\mathrm{d}}$ & $4.53^{\mathrm{e}}$ & $4.20^{f}$ & 0.061 \\
\hline Feed & 6.52 & 6.07 & 5.57 & 5.17 & 4.87 & 4.60 & \\
\hline \multicolumn{8}{|l|}{ SFA } \\
\hline Carcass & $31.60^{\mathrm{a}}$ & $30.75^{\mathrm{b}}$ & $30.32^{\mathrm{c}}$ & $28.48^{\mathrm{d}}$ & $27.25^{\mathrm{e}}$ & $26.72^{f}$ & 0.133 \\
\hline AFP & $31.10^{\mathrm{a}}$ & $28.78^{\mathrm{b}}$ & $26.47^{\mathrm{c}}$ & $23.50^{\mathrm{d}}$ & $22.30^{\mathrm{e}}$ & $20.47^{\mathrm{f}}$ & 0.100 \\
\hline Feed & 31.32 & 29.78 & 28.37 & 25.95 & 24.82 & 23.62 & \\
\hline
\end{tabular}

*Fatty acids identified as \% of total fatty acids measured.

Values in the same row with different superscripts differ significantly $(\mathrm{P}<0.05)$

Table $\mathbf{6 b}$ The monounsaturated fatty acid (MUFA) composition of the feeds, carcass and abdominal fat pad (AFP) total lipid from broilers receiving different dietary lipid variations of Famarol (FAO) and Canola (CAO) fatty acids

\begin{tabular}{|c|c|c|c|c|c|c|c|}
\hline \multicolumn{8}{|c|}{ Ratio of FAO:CAO } \\
\hline Fatty acids* & 100:0 & $80: 20$ & $60: 40$ & $40: 60$ & $20: 80$ & $0: 100$ & s.e. \\
\hline \multicolumn{8}{|l|}{ C16:1n-7 } \\
\hline$\overline{\text { Carcass }}$ & $3.20^{\mathrm{a}}$ & $3.70^{\mathrm{b}}$ & $4.37^{\mathrm{c}}$ & $4.80^{\mathrm{d}}$ & $5.62^{\mathrm{e}}$ & $6.12^{f}$ & 0.052 \\
\hline AFP & $5.60^{\mathrm{a}}$ & $5.78^{\mathrm{b}}$ & $5.87^{\mathrm{c}}$ & $5.90^{\mathrm{c}}$ & $6.03^{d}$ & $6.17^{\mathrm{e}}$ & 0.018 \\
\hline Feed & 4.43 & 4.77 & 5.15 & 5.37 & 5.85 & 6.18 & \\
\hline \multicolumn{8}{|l|}{ C18:1n-9 } \\
\hline$\overline{\text { Carcass }}$ & $37.88^{\mathrm{a}}$ & $38.55^{\mathrm{b}}$ & $40.23^{c}$ & $42.37^{\mathrm{d}}$ & $43.40^{\mathrm{e}}$ & $44.50^{\mathrm{f}}$ & 0.119 \\
\hline AFP & $39.95^{\mathrm{a}}$ & $41.90^{\mathrm{b}}$ & $42.80^{\mathrm{c}}$ & $44.75^{\mathrm{d}}$ & $45.73^{\mathrm{e}}$ & $47.23^{f}$ & 0.112 \\
\hline Feed & 38.80 & 40.17 & 41.42 & 43.47 & 44.58 & 45.90 & \\
\hline \multicolumn{8}{|l|}{ C20:1n-9 } \\
\hline Carcass & $0.95^{\mathrm{ab}}$ & $0.47^{\mathrm{a}}$ & $1.08^{\mathrm{b}}$ & $0.95^{\mathrm{ab}}$ & $1.23^{\mathrm{b}}$ & $1.12^{\mathrm{b}}$ & 0.187 \\
\hline AFP & $0.58^{\mathrm{a}}$ & $0.70^{\mathrm{a}}$ & $0.77^{\mathrm{a}}$ & $0.53^{\mathrm{a}}$ & $0.63^{\mathrm{a}}$ & $1.12^{\mathrm{b}}$ & 0.127 \\
\hline Feed & 0.80 & 0.60 & 0.93 & 0.77 & 0.97 & 1.15 & \\
\hline \multicolumn{8}{|l|}{ MUFA } \\
\hline$\overline{\text { Carcass }}$ & $44.95^{\mathrm{a}}$ & $44.63^{\mathrm{a}}$ & $46.12^{\mathrm{b}}$ & $47.68^{\mathrm{c}}$ & $48.33^{\mathrm{cd}}$ & $48.82^{\mathrm{d}}$ & 0.148 \\
\hline AFP & $46.70^{\mathrm{a}}$ & $48.63^{\mathrm{b}}$ & $49.47^{\mathrm{c}}$ & $51.15^{\mathrm{d}}$ & $52.15^{\mathrm{e}}$ & $53.95^{\mathrm{f}}$ & 0.103 \\
\hline Feed & 45.78 & 46.61 & 47.72 & 49.37 & 50.03 & 51.28 & \\
\hline
\end{tabular}

*Fatty acids identified as \% of total fatty acids measured.

Values in the same row with different superscripts differ significantly $(\mathrm{P}<0.05)$.

The 100\% FAO: $0 \%$ CAO diet contained $31.32 \%$ saturated fatty acids (SFA), which were mainly palmitic acid (C16:0) (23.38\%) and stearic acid (C18:0) (6.52\%), 45.78\% MUFA, which were predominantly oleic acid (C18:1n-9) (38.8\%) and palmitoleic acid (C16:1n-7) $(6.18 \%)$. The percentage of polyunsaturated fatty acids (PUFA, 22.9\%) consisted mainly of linoleic acid (C18:2n-6) (20.73\%) and $\alpha$ linolenic acid (C18:3n-3) (1.1\%). The 100\% FAO:0\% CAO diet showed only trace concentrations of longer chained acids. At the other extreme, the $0 \%$ FAO: $100 \%$ CAO diet had a saturated fatty acids concentration of $23.62 \%$. The main components of the SFA were palmitic acid (C16:0) (17.7\%) and stearic acid (C18:0) (4.6\%). Oleic acid (C18:1n-9) (45.9\%) was the main MUFA at a level of 51.28\%. Palmitoleic acid (C16:1n7) $(4.43 \%)$ also formed a major component of the MUFA with lower concentrations of gadoleic acid 
(C20:1n-9) being present. The 0\% FAO:100\% CAO diet had 25.12\% PUFA, with C18:2n-6 (19.17\%) and C18:3n-3 (3.3\%) being major constituents. Only trace concentrations of the longer-chained PUFA were detected in this diet.

Table 6c The polyunsaturated fatty acid (PUFA) composition of the feeds, carcass and abdominal fat pad (AFP), total lipid from broilers receiving different dietary lipid variations of Canola (CAO) and Famarol

\begin{tabular}{|c|c|c|c|c|c|c|c|}
\hline \multicolumn{8}{|c|}{ Ratio of FAO:CAO } \\
\hline Fatty acids* & 100:0 & $80: 20$ & $60: 40$ & $40: 60$ & $20: 80$ & $0: 100$ & s.e. \\
\hline \multicolumn{8}{|l|}{ C18:2n-6 } \\
\hline Carcass & $20.88^{\mathrm{a}}$ & $20.42^{b}$ & $20.13^{b c}$ & $19.78^{\mathrm{cd}}$ & $19.50^{\mathrm{d}}$ & $19.10^{\mathrm{e}}$ & 0.068 \\
\hline AFP & $20.75^{\mathrm{a}}$ & $20.50^{\mathrm{b}}$ & $20.25^{\mathrm{c}}$ & $19.88^{\mathrm{d}}$ & $19.60^{\mathrm{e}}$ & $19.20^{\mathrm{f}}$ & 0.044 \\
\hline Feed & 20.73 & 20.45 & 20.15 & 19.83 & 19.58 & 19.17 & \\
\hline \multicolumn{8}{|l|}{ C18:3n-3 } \\
\hline Carcass & $1.00^{\mathrm{a}}$ & $1.15^{\mathrm{a}}$ & $1.77^{\mathrm{b}}$ & $2.20^{\mathrm{c}}$ & $2.60^{\mathrm{d}}$ & $3.25^{\mathrm{e}}$ & 0.061 \\
\hline AFP & $1.15^{\mathrm{a}}$ & $1.37^{\mathrm{b}}$ & $1.80^{\mathrm{c}}$ & $2.58^{\mathrm{d}}$ & $2.85^{\mathrm{e}}$ & $3.28^{\mathrm{f}}$ & 0.056 \\
\hline Feed & 1.10 & 1.28 & 1.80 & 2.38 & 2.75 & 3.30 & \\
\hline \multicolumn{8}{|l|}{ C20:4n-6 } \\
\hline Carcass & $1.05^{\mathrm{a}}$ & $1.00^{\mathrm{a}}$ & $0.88^{\mathrm{b}}$ & $0.87^{\mathrm{b}}$ & $0.80^{\mathrm{b}}$ & $0.70^{\mathrm{c}}$ & 0.031 \\
\hline AFP & $1.20^{\mathrm{a}}$ & $1.10^{\mathrm{ab}}$ & $1.00^{\mathrm{bc}}$ & $0.90^{\mathrm{c}}$ & $0.42^{\mathrm{d}}$ & $0.22^{\mathrm{e}}$ & 0.038 \\
\hline Feed & 1.75 & 1.92 & 1.65 & 1.32 & 1.17 & 0.68 & \\
\hline \multicolumn{8}{|l|}{ C20:5n-3 } \\
\hline Carcass & $0.10^{\mathrm{a}}$ & $0.10^{\mathrm{a}}$ & $0.15^{\mathrm{b}}$ & $0.18^{\mathrm{bc}}$ & $0.18^{\mathrm{bc}}$ & $0.20^{\mathrm{c}}$ & 0.017 \\
\hline AFP & $0.03^{\mathrm{a}}$ & $0.08^{\mathrm{a}}$ & $0.25^{\mathrm{b}}$ & $0.35^{\mathrm{c}}$ & $0.38^{\mathrm{c}}$ & $0.48^{\mathrm{d}}$ & 0.021 \\
\hline Feed & 0.10 & 0.17 & 0.20 & 0.22 & 0.23 & 0.25 & \\
\hline \multicolumn{8}{|l|}{ C22:6n-3 } \\
\hline$\overline{\text { Carcass }}$ & $0.20^{\mathrm{a}}$ & $0.50^{\mathrm{ab}}$ & $0.48^{\mathrm{ab}}$ & $0.72^{\mathrm{bc}}$ & $0.92^{\mathrm{c}}$ & $0.87^{\mathrm{c}}$ & 0.103 \\
\hline AFP & $0.05^{\mathrm{a}}$ & $0.18^{\mathrm{a}}$ & $0.60^{\mathrm{b}}$ & $0.80^{\mathrm{bc}}$ & $0.90^{\mathrm{c}}$ & $1.00^{\mathrm{c}}$ & 0.050 \\
\hline Feed & 0.18 & 0.33 & 0.32 & 0.43 & 0.43 & 0.42 & \\
\hline \multicolumn{8}{|l|}{ PUFA } \\
\hline$\overline{\text { Carcass }}$ & $23.45^{\mathrm{a}}$ & $23.62^{\mathrm{a}}$ & $23.57^{\mathrm{a}}$ & $23.83^{\mathrm{a}}$ & $24.42^{\mathrm{b}}$ & $24.47^{\mathrm{b}}$ & 0.175 \\
\hline AFP & $23.20^{\mathrm{a}}$ & $23.58^{\mathrm{b}}$ & $24.07^{\mathrm{c}}$ & $25.35^{\mathrm{d}}$ & $25.55^{\mathrm{d}}$ & $25.58^{\mathrm{d}}$ & 0.151 \\
\hline Feed & 22.90 & 23.60 & 23.92 & 24.73 & 25.15 & 25.12 & \\
\hline \multicolumn{8}{|l|}{$\underline{n-3 / n-6}$} \\
\hline$\overline{\text { Carcass }}$ & $0.06^{\mathrm{a}}$ & $0.08^{\mathrm{a}}$ & $0.11^{\mathrm{b}}$ & $0.15^{\mathrm{c}}$ & $0.18^{\mathrm{d}}$ & $0.22^{\mathrm{e}}$ & 0.008 \\
\hline AFP & $0.06^{\mathrm{a}}$ & $0.08^{\mathrm{a}}$ & $0.12^{\mathrm{ab}}$ & $0.18^{\mathrm{bc}}$ & $0.21^{\mathrm{cd}}$ & $0.25^{\mathrm{d}}$ & 0.022 \\
\hline Feed & 0.06 & 0.08 & 0.11 & 0.14 & 0.16 & 0.20 & \\
\hline
\end{tabular}

*Fatty acids identified as $\%$ of total fatty acids measured.

Values in the same row with different superscripts differ significantly $(\mathrm{P}<0.05)$.

The means of the fatty acid profiles of the total lipids of carcass and abdominal fat pads of the broilers on the different diets are presented in Table $6 \mathrm{a}, \mathrm{b}$ and $\mathrm{c}$. The fatty acid profiles of the broiler carcasses and abdominal fat pads were significantly influenced by the content of lipid in the diet. Generally, the most common fatty acid in the diet was most abundant in the tissue and fat pads. The converse was true of the least abundant fatty acids. The levels of linoleic acid (C18:2n-6) and arachidonic acid (C20:4n-6) in the carcasses of chicks fed $100 \%$ and $80 \% \mathrm{CAO}$ were significantly lower $(\mathrm{P}<0.05)$ than those in chicks fed $100 \%$ and $80 \%$ FAO.

The differences increased with rising dietary CAO levels, whereas the levels of $\alpha$-linolenic acid (C18:3n-3), eisosapentanoic acid (EPA) (C20:5n-3) and docosahexaenoic acid (DHA) (C22:6n-3) increased linearly (Table 7). The linear regression equations in Table 7 plot the actual percentage of fatty acids in the feed over those in the tissue. The increase in dietary CAO levels also resulted in decreases in the rates of linoleic acid (C18:2n-6) and arachidonic acid (C20:4n-6) in the abdominal fat pads, but it increased the rates of $\alpha$-linolenic acid (C18:3n-3), EPA (C20:5n-3) and DHA (C22:6n-3). Therefore, the ratios of n-3/n-6 fatty acids was significantly $(\mathrm{P}<0.05)$ increased by rising the level of dietary $\mathrm{CAO}$ (Table 6$)$.

With rising levels of CAO in the diet, the SFA decreased linearly by $4.88 \%$ units and $10.63 \%$ units for the carcasses and abdominal fat pads, respectively (Table 6a). This was mainly caused by decreases in the two principal saturated fatty acids, palmitic acid (C16:0) and stearic acid (C18:0) in both tissues. Conversely, 
the mean MUFA (Table 6b) increased with 3.87\% units in the carcasses and $7.25 \%$ units in the abdominal fat pads, caused by increases in oleic acid (C18:1n-9) and palmitoleic acid (C16:1n-7). Table 6 shows a slight increase in the mean PUFA (1.02\% units for carcasses and $2.38 \%$ units for abdominal fat pads) with increased levels of CAO. This may be caused by a balancing effect of the n-3 and n- 6 fatty acids.

\section{Discussion}

There were no significant differences $(\mathrm{P}>0.05)$ in weight gain or feed conversion ratios among dietary and sex groups throughout the experimental period. This result was expected as the different diets were balanced for the energy : protein ratio. There were also no interactions between diet and sex for WG and FCR. No significant differences $(\mathrm{P}>0.05)$ were found in the proximate analysis of the carcasses and abdominal fat pads between dietary and sex groups. There was also no statistical difference in the interaction between diet and sex for these parameters.

Table 7 Linear regression equations plotting the percentage fatty acids in the feed, over the percentage in the tissue

\begin{tabular}{|c|c|c|c|c|}
\hline \multirow{2}{*}{$\begin{array}{r}\text { where } x= \\
y= \\
\text { Fatty acids } \\
\end{array}$} & $\begin{array}{l}\text { id in feed } \\
\text { id in tissue }\end{array}$ & $\begin{array}{l}\mathrm{b}=\text { slope } \\
\mathrm{a}=\text { intercept } \\
\mathrm{s}\end{array}$ & \multicolumn{2}{|c|}{ Abdominal fat } \\
\hline & $\mathrm{b} \pm$ s.e. & $a \pm$ s.e. & $b \pm$ s.e. & $\mathrm{a} \pm$ s.e. \\
\hline $\mathrm{C} 14: 0$ & $0.935 \pm 0.422$ & $0.182 \pm 0.587$ & $1.097 \pm 0.388$ & $-0.273 \pm 0.540$ \\
\hline C16:0 & $0.700 \pm 0.024$ & $7.736 \pm 0.489$ & $1.321 \pm 0.025$ & $-8.090 \pm 0.515$ \\
\hline C18:0 & $0.838 \pm 0.033$ & $1.066 \pm 0.179$ & $0.022 \pm 0.001$ & $4.117 \pm 0.040$ \\
\hline SFA & $0.659 \pm 0.025$ & $11.192 \pm 0.698$ & $1.353 \pm 0.019$ & $-11.518 \pm 0.533$ \\
\hline C16:1n-7 & $1.699 \pm 0.040$ & $-4.359 \pm 0.215$ & $0.297 \pm 0.013$ & $4.322 \pm 0.070$ \\
\hline C18:1n-9 & $0.982 \pm 0.022$ & $-0.489 \pm 0.955$ & $0.981 \pm 0.021$ & $2.161 \pm 0.893$ \\
\hline C20:1n-9 & $1.187 \pm 0.509$ & $-0.066 \pm 0.451$ & $0.772 \pm 0.298$ & $0.050 \pm 0.264$ \\
\hline MUFA & $0.821 \pm 0.051$ & $6.982 \pm 2.462$ & $1.221 \pm 0.034$ & $-8.832 \pm 1.662$ \\
\hline$C 18: 2 n-6$ & $1.117 \pm 0.047$ & $-1.231 \pm 0.893$ & $1.008 \pm 0.033$ & $0.886 \pm 0.625$ \\
\hline$C 18: 3 n-3$ & $0.980 \pm 0.035$ & $-1.016 \pm 0.111$ & $0.978 \pm 0.030$ & $-0.834 \pm 0.096$ \\
\hline$C 20: 4 n-6$ & $0.271 \pm 0.030$ & $0.499 \pm 0.045$ & $0.836 \pm 0.058$ & $-0.378 \pm 0.086$ \\
\hline$C 20: 5 n-3$ & $0.739 \pm 0.185$ & $0.009 \pm 0.037$ & $3.076 \pm 0.258$ & $-0.336 \pm 0.052$ \\
\hline$C 22: 6 n-3$ & $0.906 \pm 0.208$ & $0.002 \pm 0.150$ & $1.331 \pm 0.105$ & $-0.310 \pm 0.076$ \\
\hline PUFA & $0.440 \pm 0.097$ & $13.235 \pm 2.359$ & $1.156 \pm 0.064$ & $-3.453 \pm 1.561$ \\
\hline
\end{tabular}

SFA - saturated fatty acids, MUFA - monounsaturated fatty acid, PUFA - polyunsaturated fatty acid

In monogastric animals the fatty acid composition of the tissues will reflect that of the diet (Lands et al., 1990). Analysis of the fatty acid composition of the carcasses and abdominal fat pads showed that palmitic acid (C16:0) was the most predominant saturated fatty acid (Table 6a). Free palmitic acid (C16:0) is the primary product of fatty acid synthetase reactions within the tissues (Volpe \& Vagelos, 1973). Some myristic acid (C14:0) and lauric acid (C12:0) are also formed, and a trace of stearic acid (C18:0) may also be produced (Wakil et al., 1983). Once free palmitic acid (C16:0) is released from the synthetase complex, it can be esterified into complex lipids, elongated to stearic acid (C18:0) (the usual synthetic pathway for the de novo synthesis of stearic acid), or desaturated to palmitoleic acid (C16:1n-7) (Beare-Rogers, 1977). Different enzymatic pathways are involved in each reaction.

Oleic acid (C18:1n-9) was the most predominant MUFA in both the carcass and the abdominal fat pads (Table 6b). This was expected as fatty acid synthesis in animal systems produce only saturated acids and MUFA of the n-9 series, usually oleic acid (Volpe \& Vagelos, 1973). Animals lack the ability to desaturate mono-unsaturated fatty acids in the n- 6 or n-3 position of the fatty acid chain. In animal tissues the desaturation of the de novo synthesised fatty acids stops with the production of the MUFA with a double bond in the 9-10 position of the fatty acid chain. (If palmitate is the substrate for the dehydrogenase, the double bond will appear in the 7-8 position of the chain as the 9-10 dehydrogenase desaturates nine carbons from the carboxyl end of the molecules.) Thus, palmitoleic acid (C16:1n-7), oleic acid (C18:1n-9) and cisvaccenic acid (C18:1n-11) are the main products of this reaction. Chain elongation by another enzymatic system, the fatty acid elongase system, will produce eicosanoic acid (C20:1n-9), erucic acid (C22:1n-13) and nervonic acid (C24:1n-9) by elongation of oleic acid (Seubert \& Podack, 1973). 
Linoleic acid (C18:2n-6) was the most predominant PUFA in the tissues (Table 6c). Thomas et al. (1987) stated that individuals eating diets containing large amounts of linoleic acid will deposit this component readily in the tissue and complex lipids where it will be elongated and desaturated to arachidonic acid (C20:4n-6) (Lands et al., 1990). Sprecher \& Lee (1975) have shown that dietary PUFA are not elongated and then desaturated, but are desaturated and then elongated. The results of the present study suggest that dietary CAO enriched with $\alpha$-linolenic acid (C18:3n-3) exerts a different effect on the lipid metabolism and fatty acid composition in growing chicks from that of FAO enriched with linoleic acid. Once ingested, linoleic acid and $\alpha$-linolenic acid can be desaturated and elongated, primarily in the liver (Brenner, 1981) in such a manner that the methylene-interrupted pattern of unsaturated double bonds is maintained. The microsomal enzymatic reactions do not permit crossover between fatty acids metabolites from the linoleic acid (C18:2n-6) and $\alpha$-linolenic acid (C18:3n-3) sequences (Brenner, 1981). The desaturation and elongation steps are influenced by numerous nutritional and hormonal factors (Brenner, 1981). A competitive interaction between linoleic acid and $\alpha$-linolenic acid exists, such that n-3 PUFA suppress the metabolism of n-6 PUFA and n-6 PUFA suppress the metabolism of n-3 PUFA, although less strongly (Rahm \& Holman, 1964).

Analysis of the fatty acid composition of the carcasses and abdominal fat pads showed that the enrichment of n-3 fatty acids in those tissues is due to an increase of n-3 fatty acids as a whole in the diet, i.e. the increase of the CAO level in the diets resulted in the increased accumulation of $\alpha$-linolenic acid (C18:3n3 ) in those tissues (Table 6c). Dietary $\alpha$-linolenic acid $(\mathrm{C} 18: 3 n-3)$ is not readily incorporated into tissue lipids. It is mainly oxidised to $\mathrm{CO}_{2}$ and water (Aeberhard et al., 1978). Some is converted to EPA (C20:5n-3) and DHA (C22:6n-3), but only a small portion of the $\alpha$-linolenic acid (C18:3n-3) enters this pathway (De Gomez-Dumm \& Brenner, 1975). However, if all other fatty acids are removed from the diet and $\alpha$-linolenic acid (C18:3n-3) is fed as the only source of dietary fat, then a higher percentage is incorporated into tissue lipids (Mohrhauer \& Holman, 1963). Thus, it is a competitive discrimination that prevents $\alpha$-linolenic acid (C18:3n-3) from being stored in tissues, not an intrinsic property of this compound.

The longer chain n-3 fatty acids were deposited also into the tissues in proportion to their concentration in the diet (Table 7). This result is consistent with other reports for broiler chicks (Phetteplace \& Watkins, 1989; Olomu \& Baracos, 1991a). Studies using whole flaxseed for poultry diets have shown that whole eggs and various tissues are enriched with n-3 PUFAs derived from dietary $\alpha$-linolenic acid (C18:3n3) (Caston \& Leeson, 1990; Cherian \& Sim, 1991; Jiang et al., 1991). Docosahexaenoic acid (DHA) (C22:6n-3) can be retroconverted to eicosapentanoic acid (EPA) (C20:5n-3) which is normally present only in trace amounts in the tissue lipids. Conversely, DHA is the major long-chain n-3 fatty acid in most tissues. A few tissues contain C22:5n-3 in specific organs, but this fatty acid was not detected in this experiment. Eicosapentaenoic acid appears to have several unique pharmacological and biochemical actions when consumed in large quantities (Leaf \& Weber, 1988). In such cases, DHA, through retroconversion, supplies EPA on demand if there is an inadequate dietary supply of $\alpha$-linolenic acid.

In this investigation, there was a significant increase in $n-3 / n-6$ ratios in various tissue lipids with up to $80 \%$ or $100 \%$ CAO feeding. It is well known that there is a competitive inhibition between linoleic acid and $\alpha$-linolenic acid on desaturation reactions responsible for the synthesis of tissue PUFAs (Kinsella, 1988). This competitive inhibition depends on the ratio of the two fatty acids in a diet. Thus, an increase in dietary $\alpha$-linolenic acid (C18:3n-3) results in the reduction of $\gamma$-linolenic acid (C18:3n-6) and arachidonic acid (C20:4n-6) by inhibiting the conversion reaction from linoleic acid (C18:2n-6) to these fatty acids (Garg et al., 1989; 1990; Olomu \& Baracos, 1991b). Also n-3 and n-6 fatty acids have different reaction rates with most enzyme systems (Sprecher, 1991). Linoleic acid is rapidly incorporated into tissue and complex lipids and elongated and desaturated to arachidonic acid (Lands, et al., 1990). $\alpha$-Linolenic acid is excluded from most tissues and complex lipids (Tinoco, 1982). If large amounts of $\alpha$-linolenic acid are fed, it appears in the blood and liver in a lower proportion than fed in the diet. This is consistent with the results for carcass tissue in Table 6. Conversely, linoleic acid will usually be incorporated into complex lipids in proportionally larger amounts than what is fed in the diet, as can be seen in the results for abdominal fat in Table 6c. Thus, linoleic acid is conserved whereas $\alpha$-linolenic acid is eliminated in tissues of broilers fed high levels of linoleic acid. $\alpha$-Linolenic acid is converted to EPA and DHA, but only slowly (Adam et al., 1986), whereas linoleic acid was rapidly converted to arachidonic acid. This can be seen in the $100 \%$ FAO diet (Table 6c), resulting in a high level of C20:4n-6 (1.05\% for carcass and 1.20\% for abdominal fat) and low levels of C20:5n-3 (0.10\% for carcass and $0.03 \%$ for abdominal fat) and C22:6n-3 (0.20\% for carcass and $0.05 \%$ for abdominal fat). 
Eicosapentanoic acid does not persist in tissue (Nelson et al., 1991). It is either rapidly oxidised, or converted to DHA, a fatty acid that is strongly conserved. This is consistent with the results found in Table $6 \mathrm{c}$, showing C22:6n-3 at a constantly higher percentage in the tissues than C20:5n-3.

\section{Conclusion}

An increase in the human dietary n-3/n-6 fatty acid ratio is essential in today's Western diet to help prevent coronary heart disease by reducing plasma lipids (Kinsella et al., 1990). The results of this experiment showed that substitution of Famarol oil with Canola oil in broiler diets can increase the ratio of n-6 to n-3 fatty acids in broiler carcasses and abdominal fat pads to 5:1, a ratio more suitable for human health. Increasing the level of n-3 fatty acids in the diets was also effective in reducing the level of saturated fatty acids in the carcasses and abdominal fat pads of broiler chickens resulting in "healthier" chickens. The increased n-3 fatty acids also suppressed the formation of long-chain n-6 PUFAs derived from linoleic acid, ensuring a more balanced eicosanoid metabolism (Harris, 1989). Overall, in view of the prevalence of human coronary heart disease, consumption of n-3 PUFA enriched broilers could be considered as a useful complementary option for the amelioration of coronary vascular disease.

\section{References}

Adam, O., Wolfram, G. \& Zollner, N., 1986. Effect of $\alpha$-linolenic acid in the human diet on linoleic acid metabolism and prostaglandin biosynthesis. J. Lipid Res. 27, 421-426.

Aeberhard, E.E., Corbo, L. \& Menkes, J. H., 1978. Polyenoic acid metabolism in cultured human skin fibroblasts. Lipids 13, 758-767.

Ajuyah, A.O., Lee, K.H., Hardin, R.T. \& Sim, J.S., 1991. Changes in yield and in the fatty acid composition of whole carcass and selected meat portions of broiler chickens fed full-fat oil seeds. Poult. Sci. 70, 2304-2314.

AOAC., 1995. Official methods of analysis (16th ed.). Association of Official Analytical Chemists, Inc. Arlington, Virginia, USA,

Beare-Rogers, J.L., 1977. Docosenoic acids in dietary fats. Prog. Chem. Fats Lipids 15, 29-56.

Brenner, R.R., 1981. Nutritional and hormonal factors influencing desaturation of essential fatty acids. Prog. Lipid Res. 20, 41-47.

Caston, L. \& Leeson, S., 1990. Dietary flax and egg composition. Poult. Sci. 69, 1617-1620.

Cherian, G. \& Sim, J.S., 1991. Effect of feeding full fat flax and Canola seed to laying hens on the fatty acid composition of eggs, embryos, and newly hatched chicks. Poult. Sci. 70, 917-922.

De Gomez-Dumm, I.N.T. \& Brenner, R.R., 1975. Oxidative desaturation of $\alpha$-linolenic, linoleic and stearic acid by human microsomes. Lipids 10, 315-317.

Garg, M.L., Wierzbicki, A.A., Thomson, A.B.R. \& Clandinin, M.T., 1989. Dietary saturated fat level alters the competition between $\alpha$-linolenic and linoleic acid. Lipids 24, 334-339.

Garg, M.L., Thomson, A.B.R. \& Clandinin, M., 1990. T. Interactions of saturated, n-6 and n-3 polyunsaturated fatty acids to modulate arachidonic acid metabolism. J. Lipid Res. 31, 271-277.

Harris, W.S., 1989. Fish oils and plasma lipid and lipoprotein metabolism in humans: critical review. J. Lipid Res. 30, 785-807.

Hulan, H.W., Ackman, R.G., Ratnayake, W.M.N. \& Proudfoot, F.G., 1989. Omega-3 fatty acid levels and general performance of commercial broilers fed practical levels of redfishmeal. Poult. Sci. 68, 153162.

Jiang, Z., Ahn, D.U. \& Sim, J.S., 1991. Effects of feeding flax and two types of sunflower seeds on fatty acid compositions of yolk lipid classes. Poult. Sci. 70, 2467-2475.

Kinsella, J.E., 1988. Food lipids and fatty acids: Importance in food quality, nutrition, and health. Food Tech. 42, 124-145.

Kinsella, J.E., Lokesh, B. \& Stone, R.A., 1990. Dietary n-3 polyunsaturated fatty acids and amelioration of cardiovascular disease: possible mechanisms. Am. J. Clin. Nutr. 52, 1-28.

Lands, W.E.B., Morris, A. \& Libelt, B., 1990. Quantitative effects of dietary polyunsaturated fats on the composition of fatty acids in rat tissues. Lipids 25, 505-516.

Leaf, A. \& Weber, P.C., 1988. Cardiovascular effects of n-3 fatty acids. New Engl. J. Med. 318, 549-557.

Lee, C.M., Trevino, B. \& Chaiyawat, M., 1996. A simple and rapid solvent extraction method for determining total lipids in fish tissue. J. AOAC Intern. 79, 487-492. 
Mohrhauer, H. \& Holman, R.T., 1963. Alteration of the fatty acid composition of brain lipids by varying levels of dietary essential fatty acids. J. Neurochem. 10, 523-530.

Morrison, W.R. \& Smith, M.L., 1964. Preparation of fatty acid methyl esters and dimethylacetals from lipids with boron fluoride-methanol. J. Lipid Res. 5, 600-602.

Nelson, G.J., Schmidt, P.C. \& Corash, L., 1991. The effect of a salmon diet on blood clotting, platelet aggregation and fatty acids in normal adult men. Lipids 26, 87-96.

Olomu, J.M. \& Baracos, V.E., 1991a. Influence of dietary flaxseed oil on the performance, muscle protein deposition, and fatty acid composition of broiler chicks. Poult. Sci. 70, 1403-1411.

Olomu, J.M. \& Baracos, V.E., 1991b. Prostaglandin synthesis and fatty acid composition of phospholipids and triglycerides in skeletal muscle of chicks fed combinations of flaxseed oil and animal tallow. Lipids 26, 743-749.

Phetteplace, H.W. \& Watkins, B.A., 1989. Effects of various n-3 lipid sources on fatty acid compositions in chicken tissues. J. Food Comp. Anal. 2, 104-117.

Rahm, J.J. \& Holman, R.T., 1964. Effect of linoleic acid upon the metabolism of linolenic acid. J. Nutr. 84, $15-19$.

Seubert, W. \& Podack, E.R., 1973. Mechanisms and physiological rates of fatty acid chain elongation in microsomes and mitochondria. Mol. Cell. Bioch. 1, 29-40.

Simopoulos, A.P., 1991. Omega-3 fatty acids in health and disease and in growth and development. Am. J. Clin. Nutr. 54, 438-463.

Sprecher, H. \& Lee, C.J., 1975. The absence of an 8-desaturase in rat liver: a re-evaluation of optimal pathways for the metabolism of linoleic and linolenic acids. Biochim. Biophys. Acta 388, 113-125.

Sprecher, H., 1991. Metabolism of dietary fatty acids. In: Health effects of dietary fatty acids. Ed. Nelson, G.J., American Oil Chemists' Society, Champaign, III, pp.12-20.

SAS, 1985. Statistical Analysis System user's guide (6th ed.), SAS Institute, Inc., Cary, North Carolina.

Thomas, L.H., Olpin, S.O., Scott, R.G. \& Wilkins, M.P., 1987. Coronary heart disease and the composition of adipose tissue taken at biopsy. Human Nutr.: Food Sci. Nutr. 41F, 167-172.

Tinoco, J., 1982. Dietary requirements and functions of $\alpha$-linolenic acid in animals. Prog. Lipid Res. 21, 145.

Volpe, J.J. \& Vagelos, P.R., 1973. Saturated fatty acid biosynthesis. Ann. Rev. Biochem. 42, 21-60.

Wakil, S.J., Stoops, J.K. \& Joshi, V.C., 1983. Fatty acid synthesis and its regulation. Ann. Rev. Biochem. 52, 537-579.

Wiseman, M.J., 1997. Fat and fatty acids in relation to cardiovascular disease: an overview. Br. J. Nutr. 78 (Suppl. 1), S3-S4. 